\title{
Comparative evaluation of the depth of cure and surface roughness of bulk-fill composites: An in vitro study
}

\section{Ocena porównawcza głębokości utwardzenia i chropowatości powierzchni materiałów kompozytowych typu bulk-fill - badanie in vitro}

\author{
Anusha Parasher ${ }^{1, A, D}$, Kishore Ginjupalli ${ }^{2, A, C-F}$, Krishnaraj Somayaji ${ }^{1, A-F}$, Pradeep Kabbinale ${ }^{3, B}$ \\ 1 Department of Conservative Dentistry and Endodontics, Manipal College of Dental Sciences, Manipal Academy of Higher Education, Manipal, India \\ ${ }^{2}$ Department of Dental Materials, Manipal College of Dental Sciences, Manipal Academy of Higher Education, Manipal, India \\ ${ }^{3}$ Department of Conservative Dentistry and Endodontics, Subbaiah Institute of Dental Sciences, Shimoga, India \\ A - research concept and design; $\mathrm{B}$ - collection and/or assembly of data; $\mathrm{C}$ - data analysis and interpretation; \\ $D$ - writing the article; $E$ - critical revision of the article; $F$ - final approval of the article
}

Address for correspondence

Krishnaraj Somayaji

E-mail: sksomayaj@gmail.com

Funding sources

None declared

Conflict of interest

None declared

Received on May 22, 2019

Reviewed on 0ctober 7, 2019

Accepted on 0ctober 12, 2019

Published online on January 28, 2020

Cite as

Parasher A, Ginjupalli K, Somayaji K, Kabbinale P. Comparative evaluation of the depth of cure and surface roughness of bulk-fill composites: An in vitro study. Dent Med Probl. 2020;57(1):39-44. doi:10.17219/dmp/113003

DOI

$10.17219 / \mathrm{dmp} / 113003$

Copyright

๑ 2020 by Wroclaw Medical University

This is an article distributed under the terms of the

Creative Commons Attribution 3.0 Unported License (CC BY 3.0)

(https://creativecommons.org/licenses/by/3.0/)

\begin{abstract}
Background. Composites are in great demand due to the esthetic needs of the patients, which explains a wide variation in the types of available composites. However, the mechanical strength of the materials is questionable. Therefore, the mechanical properties of the newly available bulk-fill composites have been tested.

Objectives. The main objective of the study was to compare the depth of cure (DOC) and surface roughness of 3 different bulk-fill composites: X-tra fil ${ }^{\circledR}$ (XTF), Tetric EvoCeram ${ }^{\circledR}$ Bulk Fill (TEC) and Beautifil ${ }^{\circledR}$ Bulk Restorative (BBR).

Material and methods. Fifty-seven ( $n=19$ in each group) samples were made using brass molds. All samples were subjected to Vickers hardness testing and profilometry. The one-way analysis of variance (ANOVA) test was used for the data analysis, followed by Tukey's post hoc test.

Results. The differences in the mean surface microhardness values of the materials were statistically significant $(p<0.001)$, with XTF showing the highest value. The TEC composite showed a higher surface roughness as compared to BBR and XTF.

Conclusions. The results of the present study indicate that variations in the filler size and amount significantly influence the DOC and surface roughness of dental composites. Among the tested composites, the multi-hybrid composite exhibited superior DOC (XTF), whereas the nanohybrid composite exhibited superior surface finish (TEC).
\end{abstract}

Key words: hardness, surface roughness, bulk-fill composites, depth of cure

Słowa kluczowe: wytrzymałość, chropowatość powierzchni, materiały kompozytowe typu bulk-fill, głębokość utwardzenia 


\section{Introduction}

The growing demand for life-like restorations and the motivation of some dentists to provide mercuryfree, tooth-colored restorations have led to an increase in the use of resin-based composite (RBC) materials. Some of the advantages of composite restorations include better esthetics, reduced need for extensive tooth preparation and reinforcement of the remaining tooth structure. $^{1}$

At present, most RBCs are supplied as light-activated materials and their clinical placement requires the incremental layering technique. ${ }^{2}$ The material has to be placed in layers to allow light penetration, which would ensure complete polymerization. This process is timeconsuming and may lead to the inclusion of voids in the restoration. In addition, non-uniform curing may lead to uncured RBCs at the bottom or in between the increments, resulting in the restoration with inadequate strength and marginal leakage, and thus of a reduced longevity. Furthermore, uncured RBCs may also cause postoperative sensitivity. To overcome the disadvantages of the conventional incremental placement of RBCs, bulk-fill composites were introduced to reduce the chair time and to offer a less techniquesensitive material. ${ }^{3}$ Bulk-fill composites are newer restorative materials which are said to present improved cure, controlled polymerization contraction stresses and a reduced cuspal deflection; they are effectively photoactivated in layers up to $4 \mathrm{~mm}$, and as such can be used in deep preparations. ${ }^{4,5}$

A higher translucency observed in bulk-fill composites as compared to conventional resin composites enables superior light transmission, and thus better polymerization. A higher percentage degree of conversion (DC) displayed by bulk-fill composites is due to better light penetration, as the materials exhibit a reduced opacity. Other factors, such as the filler content, size modifications or the use of a monomer of a higher molecular mass in the resin, also significantly influence the translucency of these materials. ${ }^{6}$

Several bulk-fill composites are now available on the market, claimed to exhibit superior depth of cure (DOC), exceeding $4 \mathrm{~mm}$. Among these, X-tra fil ${ }^{\circledR}$ (XTF) (Voco GmbH, Cuxhaven, Germany), a posterior composite based on the multi-hybrid filler technology, is available in a universal shade, which can be cured up to a depth of $4 \mathrm{~mm}$ in $10 \mathrm{~s}$. It consists of bisphenol A-glycidyl methacrylate (Bis-GMA), urethane dimethacrylate (UDMA), triethylene glycol dimethacrylate (TEGDMA), and the barium-boron-aluminosilicate (Ba-B-Al-Si) glass filler. By adjusting the filler size, an extremely high filler content ( $86 \mathrm{wt} \%$ ) has been achieved in the material, with a consequent increase in wear resistance and a lower polymerization shrinkage. In addition, it also exhibits superior radiopacity.
Tetric EvoCeram ${ }^{\circledR}$ Bulk Fill (TEC) (Ivoclar Vivadent AG, Schaan, Liechtenstein) is a nanohybrid composite containing dimethacrylates, which make up 20-21 wt\% of the monomer matrix. Fillers such as ytterbium trifluoride $\left(\mathrm{YbF}_{3}\right)$, barium (Ba) glass, mixed oxides, and a prepolymer constitute up to about 79-81 wt\%. The particle size of the filler varies between 40 and 3,000 nm, with a mean particle size of $500 \mathrm{~nm}$. It also contains Ivo$\operatorname{cerin}^{\circledR}$, a photoinitiator, which allows DOC of $4 \mathrm{~mm}$ and makes it possible to minimize the shrinkage stress.

Beautifil ${ }^{\circledR}$ Bulk (Shofu Dental Corporation, San Marcos, USA) is prepared based on the pre-reacted glass (PRG) technology, in which acid-reactive fluoride glass is made to react with polyacid in the presence of water, after which it is milled, silanized and ground to fine powder for use as a filler in the resin matrix. The resin matrix comprises Bis-GMA, UDMA, 2,2-bis[(4-methacryloxy polyethoxy)phenyl]propane (Bis-MPEPP), and TEGDMA. It is a radiopaque light-cured material with a 4-millimeter DOC. Apart from being biocompatible, this material has the ability to reduce tooth demineralization by releasing fluoride, which also imparts anti-plaque activity. ${ }^{7}$ It is available in low viscosity (Beautifil Bulk Flowable) as well as in packable consistency (Beautifil Bulk Restorative - BBR).

Though the compositional differences account for significant differences in the properties of the commercially available composites, it is of utmost importance to ensure the complete polymerization and highly polished surfaces of these materials during clinical placement. Surface texture has a great influence on plaque accumulation, and on the discoloration, wear and esthetic appearance of the restoration. ${ }^{8}$ The polishability of RBCs is directly affected by the structure of the organic matrix and the characteristics of the fillers.

In addition, the extent of polymerization of RBCs also influences their physical, mechanical and biological characteristics. Incomplete polymerization due to the inadequate curing of RBCs may impair their physical and mechanical properties, and even make them toxic to the pulp. Surface hardness has been widely used in the literature as an indicator of the extent of polymerization of dental composites. An arbitrary minimum value of the bottom-to-top surface hardness ratio is commonly calculated to establish the DOC of RBCs. For a material to be considered as adequately cured, the value of the ratio needs to be in the range of $0.8-0.85 .^{7}$

The various available bulk-fill composites certainly widen the selection of tooth-colored restorative materials and help reduce the chair time during the placement of the restoration due to generally better DOC. However, the performance and longevity of such materials largely depend on the exact DOC and complete polymerization. Hence, the aim of the present study was to evaluate the surface roughness and DOC of commercially available bulk-fill composites, such as XTF, TEC and BBR. 


\section{Material and methods}

Three packable bulk-fill composites - XTF, TEC and BBR - in universal A shades (IVA) were used in the present study. The IVA shade was selected to minimize the effects of colorants on light polymerization.

\section{Specimen preparation}

A total of 57 samples were prepared, 19 samples from each of the 3 selected bulk-fill composite materials (Fig. 1). The specimens were prepared using a custommade brass mold, consisting of 5 cylindrical slots of a diameter of $10 \mathrm{~mm}$ and a height of $4 \mathrm{~mm}$ (Fig. 2). The mold was filled using a single increment of the composite material and covered with a Mylar strip. The mold was pressed between 2 transparent glass plates to remove the excess material. Subsequently, the composite was lightcured according to the manufacturer's recommendations, using the Bluephase ${ }^{\circledR}$ G2 light-cure device (Ivoclar Vivadent AG) within the range of 1,200-1,400 Mw/ $\mathrm{cm}^{2}$. The tip of the curing device was kept in direct contact with the glass plate to maintain the standardized distance from the tip of the device to the top surface of the specimen.

After curing, the samples were retrieved and polished using the Super-Snap disks (Shofu Dental Corporation) at coarse, medium, fine, and superfine grits for $30 \mathrm{~s}$. After each step of polishing, the specimens were thoroughly rinsed with water and air-dried before the next step until final polishing. The samples were stored in artificial saliva at $37^{\circ} \mathrm{C}$ for $24 \mathrm{~h}$ before testing. All specimens were observed under a bright light source, and specimens with any voids or cracks were not included in the study (Fig. 3).

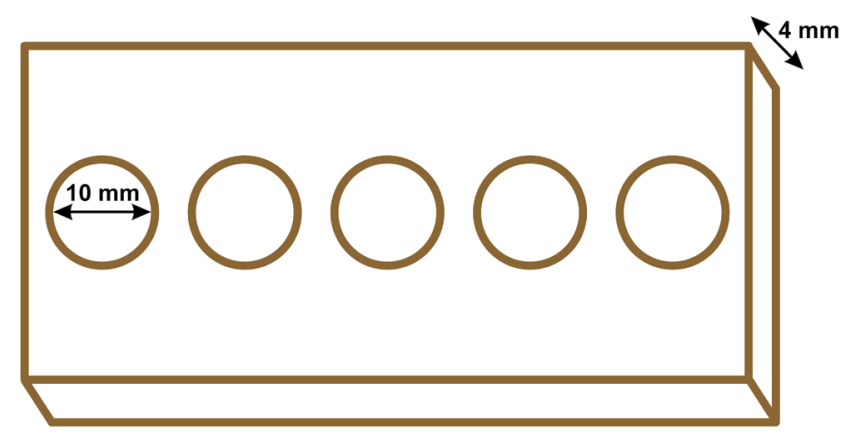

Fig. 2. Schematic representation of a brass mold used for specimen preparation

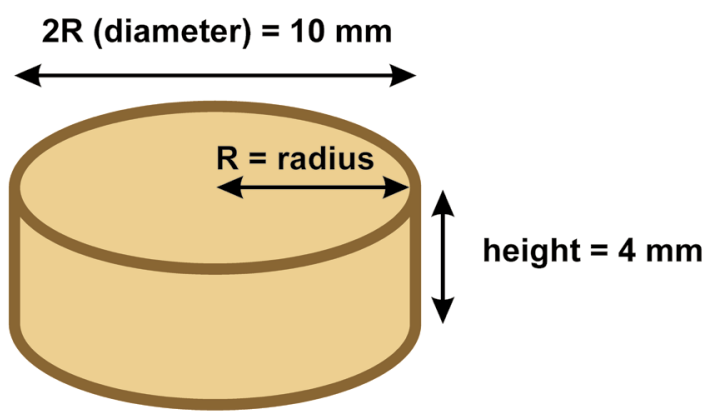

Fig. 3. Schematic representation of a composite specimen

\section{Depth of cure by the Vickers hardness testing method}

The surface hardness of the specimens was measured on both the top and bottom surfaces using the Vickers hardness tester (MMT-X7A; Matsuzawa Co. Ltd., Tokyo, Japan). The specimens were secured onto a platform and were subsequently indented with a square-based diamond pyramid indenter with a load of $300 \mathrm{~g}$ for $15 \mathrm{~s}$, with an automatic loading and release mechanism. Then, the lengths

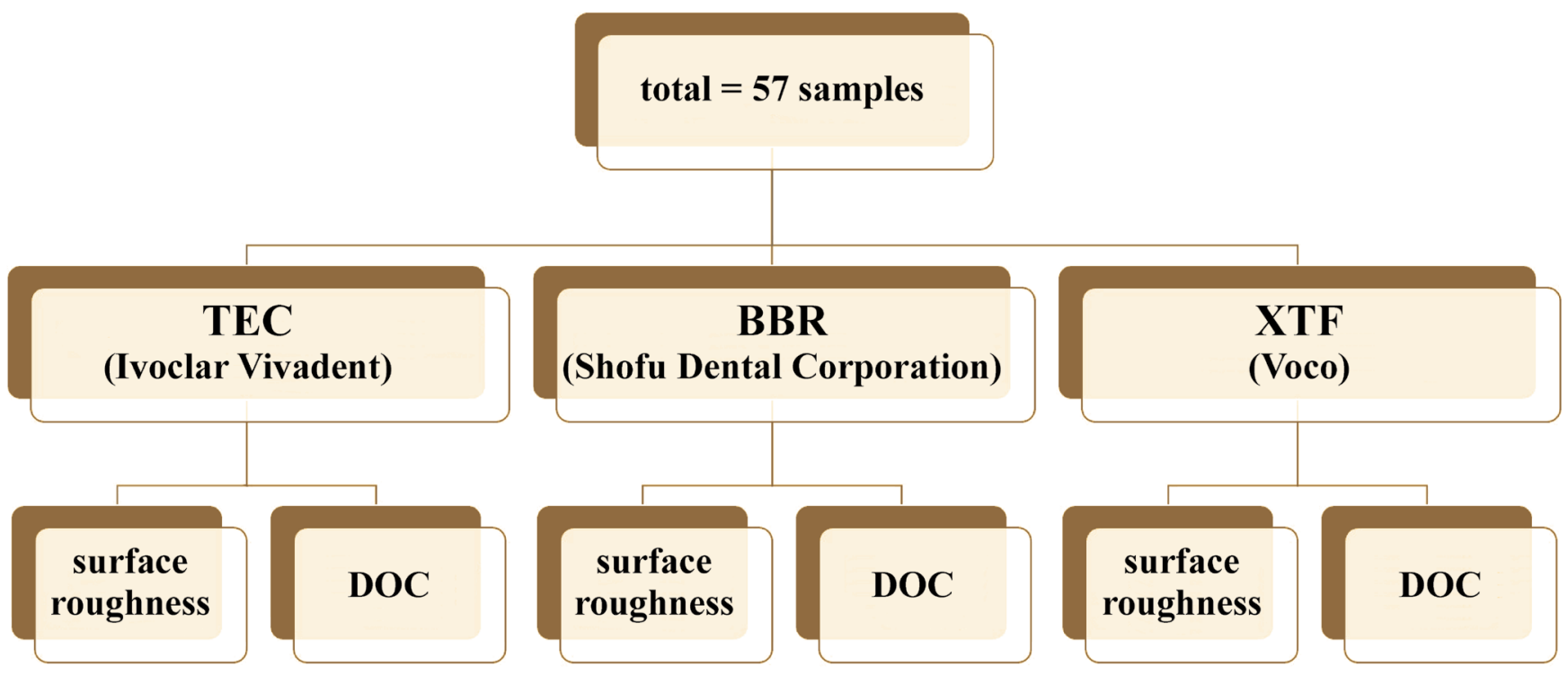

Fig. 1. Study design

XTF - X-tra fil; BBR - Beautifil Bulk Restorative; TEC - Tetric Evoceram Bulk Fill; DOC - depth of cure. 
of the diagonals of the indentations were measured using a built-in microscope, and the surface hardness for each indentation was automatically calculated and displayed on the digital readout of the machine. Three different indentations were done on both the top and bottom surfaces of each specimen. The surface hardness values measured on the top of the specimen were considered as $100 \%$, and the values measured at a 4-millimeter distance were expressed as a percentage of the top surface hardness value and were obtained using the following formula:

$$
\mathrm{VHN}=\frac{\text { bottom VHN }}{\text { top VHN }} \times 100 \quad[\%]
$$

where:

VHN - Vickers hardness number.

\section{Surface roughness measurement}

After polishing, the composite surfaces were assessed quantitatively for surface roughness using profilometry (Taly$\operatorname{surf}^{\mathbb{R}}$; Taylor-Hobson Ltd., Leicester, UK) with a measurement range of $0.05-10.0 \mu \mathrm{m}$ and an accuracy of $\pm 0.01 \mu \mathrm{m}$. Surface roughness was described with the arithmetic mean of the absolute ordinate values (average roughness $\mathrm{Ra}$, as per ISO 4287). The specimens were secured onto a non-vibrating specimen holder and the stylus of the profilometer was lowered onto the specimen perpendicularly. Surface roughness was measured by moving the stylus along a 0.8 -millimeter length of the surface at 3 different locations on each surface.

\section{Statistical analysis}

The obtained results were then subjected to the statistical analysis using the PASW Statistics for Windows software, v. 18.0 (SPSS Inc., Chicago, USA). The one-way analysis of variance (ANOVA) with Tukey's post hoc test for intergroup comparison were performed, and a $p$-value of $<0.05$ was considered statistically significant.

\section{Results}

The main aim of the present study was to evaluate the surface roughness and surface hardness of 3 commercially available bulk-fill composites. The mean top surface microhardness values for the XTF, BBR and TEC composite resins were found to be $91.87 \pm 3.68,61.92 \pm 2.22$ and $45.44 \pm 3.05$ VHN, respectively (Fig. 4 , Table 1 ). The mean surface microhardness values at a depth of $4 \mathrm{~mm}$ (the bottom surface of the specimen) for the XTF, BBR and TEC composite resins were found to be $73.97 \pm 2.96$, $46.78 \pm 2.34$ and $35.40 \pm 1.81 \mathrm{VHN}$, respectively (Fig. 4, Table 1). The observed differences between the materials in the surface hardness values on both the top and bottom surfaces were found to be statistically significant $(p<0.001)$. Among the composites, XTF showed a significantly higher surface hardness than other materials on both surfaces $(p<0.001)$. As compared to TEC, a significantly higher surface hardness was observed for the BBR composite $(p<0.001)$.

The calculated DOC at $4 \mathrm{~mm}$ for the composite materials used in the present study was found to be $80.62 \pm 4.20$, $75.56 \pm 2.67$ and $78.24 \pm 6.72$ for XTF, BBR and TEC, respectively (Table 1 ). The DOC of XTF was significantly higher in comparison with other materials $(p<0.001)$.

The mean surface roughness, $\mathrm{Ra}$, is presented in Fig. 5. The mean surface roughness of XTF and BBR was found to be $0.04 \pm 0.02$ and $0.04 \pm 0.01 \mu \mathrm{m}$, respectively, which means a statistically non-significant difference (Table 1 ). However, the mean surface roughness of TEC was found to be $0.06 \pm 0.01 \mu \mathrm{m}$, which is significantly different from that for $\operatorname{BBR}(p<0.001)$.

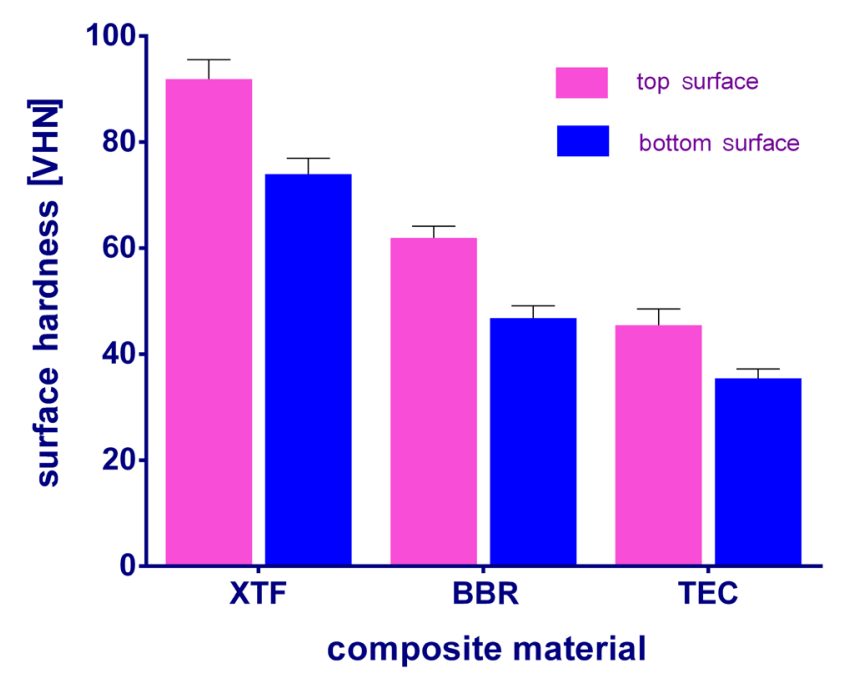

Fig. 4. Top and bottom surface hardness of the composite materials VHN - Vickers hardness number.

Data presented as mean \pm standard deviation (SD).

Table 1. Comparison of surface hardness at the top and bottom (a 4-millimeter depth) surfaces, DOC and surface roughness (Ra) of the composite resins

\begin{tabular}{|c|c|c|c|c|c|}
\hline Property & $\mathrm{XTF}^{1}$ & $\mathrm{BBR}^{2}$ & $\mathrm{TEC}^{3}$ & $p$-value & post hoc test \\
\hline Surface hardness at the top surface [VHN] & $91.87 \pm 3.68$ & $61.92 \pm 2.22$ & $45.44 \pm 3.05$ & $<0.001$ & $1>2>3$ \\
\hline Surface hardness at the bottom surface [VHN] & $73.97 \pm 2.96$ & $46.78 \pm 2.34$ & $35.40 \pm 1.81$ & $<0.001$ & $1>2>3$ \\
\hline DOC & $80.62 \pm 4.20$ & $75.56 \pm 2.67$ & $78.24 \pm 6.72$ & $<0.001$ & $1>3>2$ \\
\hline Surface roughness $(\mathrm{Ra})[\mu \mathrm{m}]$ & $0.04 \pm 0.02$ & $0.04 \pm 0.01$ & $0.06 \pm 0.01$ & $<0.001$ & $3>2,1$ \\
\hline
\end{tabular}

Data expressed as mean $\pm S D$. 


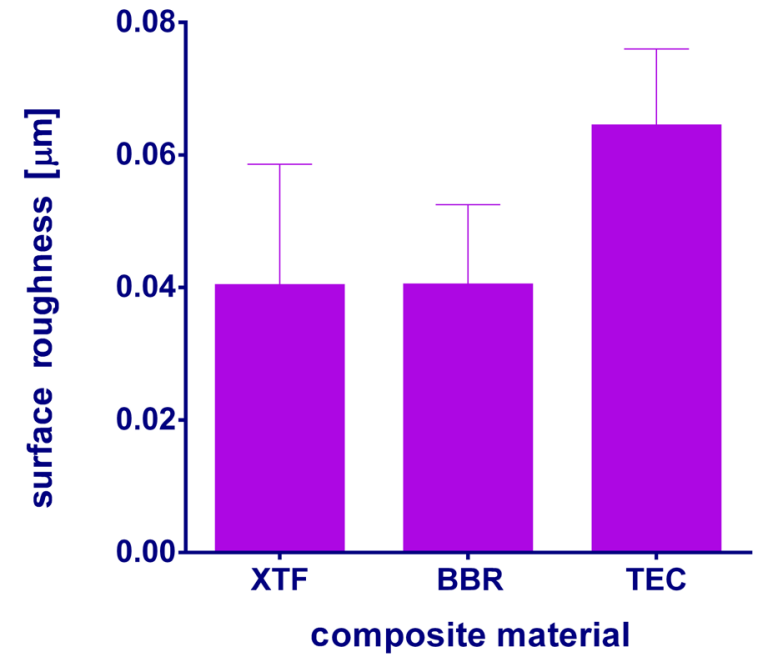

Fig. 5. Surface roughness ( $R a)$ of the composite materials Data presented as mean $\pm S D$.

\section{Discussion}

Ultimately, any dental restorative material is to mimic the biological, functional and esthetic properties of a healthy tooth structure. Over the years, there has been an increasing need for better tooth-colored restorative materials to replace the missing tooth structure. The development of resin composite materials for direct restorations with improved physical and mechanical properties, esthetics and durability has been the focus of research in the recent past. ${ }^{9}$ The most common strategies to improve the properties of dental composites include modifications in the filler content, and variations in the size, type and morphology of the filler particles and the organic matrix..$^{10}$ Together, these changes have resulted in the higher mechanical strength and modulus of elasticity of newer resin composite materials.

To facilitate the reduction of the clinical working time of composite resin placement, bulk-fill composites were developed with a single curing depth of $4 \mathrm{~mm}$. Currently, they are available as low-viscosity bulk-fill composites for use as a base or high-viscosity bulk-fill composites for restorative purposes. ${ }^{11}$ The manufacturers of bulk-fill composite materials claim their higher DOC, and over the years, multiple techniques have been investigated to accurately measure the DOC of composite resins. Among these, ISO 4049 or the scraping technique is widely used to determine hardness; still, for bulk-fill RBCs, this technique tends to be overrated. Some authors have demonstrated a good correlation between hardness testing and DC using Raman or Fourier transform infrared (FTIR) spectroscopy for measuring the DOC of composite resins. ${ }^{12}$ However, in the present study, the Vickers microhardness tester was used to evaluate the DOC of the experimental resin composites. This method is easy and quick, and requires a minimal area of the specimen surface for testing. ${ }^{12-14}$ The size of the Vickers hardness indenter is larger than the size of the filler particles in the material complex; as a result, VHN takes into account not only the filler component, but also the surrounding softer resin matrix. In this regard, VHN indirectly considers the entire matrix network crosslinking. ${ }^{15,16}$ A low surface hardness value is largely related to inadequate wear resistance and susceptibility to scratch damage, which can compromise the fatigue strength of the restoration and lead to its failure. ${ }^{17,18}$

In this study, XTF showed the highest DOC in comparison with the other 2 materials. A high DOC shown by XTF can be attributed to the presence of macrofillers $(>20 \mu \mathrm{m})$ in XTF, increasing its translucency, which in turn may have led to an increased DOC. However, the difference between the values for XTF and TEC proved to be statistically nonsignificant. Both TEC and BBR showed lower DOC values in a descending order, though the difference was not statistically significant. X-tra fil is a multi-hybrid composite with $86 \mathrm{wt} \%$ of the Ba-B-Al-Si glass filler. Tetric EvoCeram Bulk Fill contains $79-81 \mathrm{wt} \%$ of $\mathrm{YbF}_{3}$, Ba glass, mixed oxides, and a prepolymer. On the other hand, BBR contains $87 \mathrm{wt} \%$ or $74.5 \mathrm{vol} \%$ of fluorine-boron-aluminosilicate (F-B-Al-Si) glass as a filler. Light reflection from RBCs, deflection of light from the filler particles and light absorption by the photoinitiators lead to a reduction in light penetration into the depth of conventional composites, thus limiting their DOC to $2 \mathrm{~mm}$. The filler composition as well as the filler size play an important role in light diffusion in RBCs, determining their DOC. Bulkfill RBCs have an increased filler size (macrofillers). Light penetration is higher due to a reduced surface area of the macrofillers with a reduced resin-filler interface, and hence DOC is increased. Similarly, some of the low-viscosity bulkfill composites with a lower filler content also exhibit a higher DOC. ${ }^{19}$

A decreased DOC of TEC could be due to the difference in the photoinitiator system. This composite contains Ivocerin and (2,4,6-trimethylbenzoyl)diphenylphosphine oxide (TPO) as photoinitiators, which are suggested to increase DC as compared to camphorquinone (CQ). However, in this study TEC showed a lower DOC than XTF. This may be explained by the filler size in TEC, which is smaller than in the case of XTF, leading to a higher light reflection and a decreased translucency, which in turn reduces DOC..$^{20}$ The BBR composite showed the lowest DOC among the tested materials. This could be attributed to an increased filler content ( $87 \mathrm{wt} \%$ or $74.5 \mathrm{vol} \%$ ), which may reduce the translucency of the material. ${ }^{21}$ These results are in agreement with previous studies suggesting that filler loading and the filler particle size influence the DOC of composite resins. 19,21,22

The longevity of the RBC restoration depends on its resistance to wear in the oral cavity, which is influenced by a variety of factors, such as the magnitude of forces of mastication, the patient's diet, temperature variations, bacterial products, enzymes, etc. ${ }^{23-25}$ Mylar strips enhance surface smoothness, but, clinically, restorations need contouring in order to eliminate the excess material. Various polishing systems are available on the market. However, in this study, the single polishing system with multi-step polishing SuperSnap was used as a standardized method. ${ }^{26}$ Profilometry 
and atomic force microscopy (AFM) have been commonly used to assess surface roughness. A well-established method for checking surface roughness is stylus profilometry, which is simple and easy to perform. ${ }^{27}$

In this study, TEC showed the highest surface roughness as compared to XTF and BBR. The filler content in TEC is lower (79-81 wt\%) than in other composites. Conventionally, it has been observed that RBCs with bigger filler particles show a greater surface roughness following polishing. In this study, the Super-Snap disks were used for polishing and the scope for polishing in the different materials could have varied. ${ }^{28}$ The similar surface roughness of BBR and XTF can be attributed to the similar filler size and content (by weight). The results of the present study indicate that the surface roughness of RBCs is significantly influenced by the filler size and content. ${ }^{29}$ However, the polishability and the resultant surface roughness are also affected by other factors, such as the abrasive agent used, the amount of time each abrasive agent is used, pressure, the number of uses, and the direction in which the abrasive agent is used. ${ }^{30}$

\section{Conclusions}

Within the limitations of the present study, it can be concluded that the DOC and surface roughness of the tested materials were significantly different. Among the materials evaluated in the present study, XTF exhibited superior DOC as compared to TEC and BBR. The TEC composite exhibited a higher surface roughness than XTF and BBR.

\section{ORCID iDs}

Anusha Parasher (10) https://orcid.org/0000-0002-7866-3790 Kishore Ginjupalli (D) https://orcid.org/0000-0002-1824-2054 Krishnaraj Somayaji (1) https://orcid.org/0000-0002-5116-4617 Pradeep Kabbinale (1) https://orcid.org/0000-0002-5562-2398

\section{References}

1. Benetti A, Havndrup-Pedersen C, Honoré D, Pedersen MK, Pallesen U. Bulk-fill resin composites: Polymerization contraction, depth of cure, and gap formation. Oper Dent. 2015;40(2):190-200.

2. Roeters JJ, Shortall AC, Opdam NJ. Can a single composite resin serve all purposes? Br Dent J. 2005;199(2):73-79;quiz 114.

3. Gonçalves F, Campos LMP, Rodrigues-Júnior EC, et al. A comparative study of bulk-fill composites: Degree of conversion, post-gel shrinkage and cytotoxicity. Braz Oral Res. 2018;32:e17.

4. Garoushi S, Vallittu P, Shinya A, Lassila L. Influence of increment thickness on light transmission, degree of conversion and micro hardness of bulk fill composites. Odontology. 2015;104(3):291-297.

5. Tanthanuch S, Kukiattrakoon B, Eiam-O-Pas K, et al. Surface changes of various bulk-fill resin-based composites after exposure to different food-simulating liquid and beverages. J Esthet Restor Dent. 2018;30(2):126-135.

6. Itota T, Carrick TE, Yoshiyama M, McCabe JF. Fluoride release and recharge in giomer, compomer and resin composite. Dent Mater. 2004;20(9):789-795.

7. Moore BK, Platt JA, Borges G, Chu TM, Katsilieri I. Depth of cure of dental resin composites: ISO 4049 depth and microhardness of types of materials and shades. Oper Dent. 2008;33(4):408-412.

8. Morgan M. Finishing and polishing of direct posterior resin restorations. Pract Proced Aesthet Dent. 2004;16(3):211-218.
9. Hegde MN, Hegde P, Bhandary S, Deepika K. An evaluation of compressive strength of newer nanocomposite: An in vitro study. J Conserv Dent. 2011;14(1):36-39.

10. Pallesen U, van Dijken JW, Halken J, Hallonsten AL, Höigaard R. Longevity of posterior resin composite restorations in permanent teeth in Public Dental Health Service: A prospective 8 years follow up. J Dent. 2013;41(4):297-306.

11. Kelić $\mathrm{K}$, Matić $\mathrm{S}$, Marović $\mathrm{D}$, Klarić $\mathrm{E}$, Tarle Z. Microhardness of bulkfill composite materials. Acta Clin Croat. 2016:55(4):607-614.

12. Bouschlicher MR, Rueggeberg FA, Wilson BM. Correlation of bottomto-top surface microhardness and conversion ratios for a variety of resin composite compositions. Oper Dent. 2004;29(6):698-704.

13. Flury S, Hayoz S, Peutzfeldt A, Hüsler J, Lussi A. Depth of cure of resin composites: Is the ISO 4049 method suitable for bulk fill materials? Dent Mater. 2012;28(5):521-528.

14. Chuenarrom C, Benjakul P, Daosodsai P. Effect of indentation load and time on Knoop and Vickers microhardness tests for enamel and dentin. Mater Res. 2009;12(4):473-476.

15. Hosseinalipour M, Javadpour J, Rezaie H, Dadras T, Hayati AN. Investigation of mechanical properties of experimental Bis-GMA/ TEGDMA dental composite resins containing various mass fractions of silica nanoparticles. J Prosthodont. 2010;19(2):112-117.

16. Asmussen E, Peutzfeld A. Influence of pulse-delay curing on softening of polymer structures. J Dent Res. 2001;80(6):1570-1573.

17. Tchorz JP, Doll R, Wolkewitz M, Hellwig E, Hannig C. Microhardness of composite materials with different organic phases in deep class II cavities: An in vitro study. Oper Dent. 2011;36(5):502-511.

18. Erdemir U, Yildiz E, Eren MM, Ozel S. Surface hardness evaluation of different composite resin materials: Influence of sports and energy drinks immersion after a short-term period. J Appl Oral Sci. 2013:21(2):124-131.

19. Bucuta S, llie N. Light transmittance and micro-mechanical properties of bulk fill vs. conventional resin based composites. Clin Oral Investig. 2014;18(8):1991-2000.

20. Czasch P, llie N. In vitro comparison of mechanical properties and degree of cure of bulk fill composites. Clin Oral Investig. 2013;17(1):227-235.

21. Dionysopoulos D, Tolidis K, Gerasimou P. The effect of composition, temperature and post-irradiation curing of bulk fill resin composites on polymerization efficiency. Mater Res. 2016;19(2):466-473.

22. Tuncer S, Demirci M, Öztaş E, Tekçe N, Uysal Ö. Microhybrid versus nanofill composite in combination with a three step etch and rinse adhesive in occlusal cavities: Five year results. Restor Dent Endod. 2017;42(4):253-263.

23. Drummond JL. Degradation, fatigue and failure of resin dental composite materials. J Dent Res. 2008;87(8):710-719.

24. Opdam NJ, Bronkhorst EM, Loomans BA, Huysmans MC. 12-year survival of composite vs. amalgam restorations. J Dent Res. 2010;89(10):1063-1067.

25. Atai M, Nekoomanesh M, Hashemi SA, Amani S. Physical and mechanical properties of an experimental dental composite based on a new monomer. Dent Mater. 2004;20(7):663-668.

26. Pereira CA, Eskelson E, Cavalli V, Liporoni PC, Jorge AO, do Rego MA. Streptococcus mutans biofilm adhesion on composite resin surfaces after different finishing and polishing techniques. Oper Dent. 2011;36(3):311-317.

27. Neme AL, Frazier KB, Roeder LB. Debner TL. Effect of prophylactic polishing protocols on the surface roughness of esthetic restorative materials. Oper Dent. 2002:27(1):50-58.

28. Kaizer MR, de Oliveira-Ogliari A, Cenci MS, Opdam NJ, Moraes RR. Do nanofill or submicron composites show improved smoothness and gloss? A systematic review of in vitro studies. Dent Mater. 2014:30(4):e41-e78.

29. Mohammadi N, Kimyai S, Abed-Kahnamoii M, Ebrahimi-Chaharom ME, Sadr A, Daneshi M. Effect of $15 \%$ carbamide peroxide bleaching gel on color stability of giomer and microfilled composite resin: An in vitro comparison. Med Oral Pathol Oral Cir Bucal. 2012;17(6):e1082-e1088.

30. Jefferies SR. Abrasive finishing and polishing in restorative dentistry: A state-of-the-art review. Dent Clin North Am. 2007;51(2):379-397. 